\title{
ГОСУДАРСТВЕННО-ЧАСТНОЕ ПАРТНЕРСТВО ПРИ РЕАЛИЗАЦИИ РЕГИОНАЛЬНОГО ПРОЕКТА «ЭКОЛОГИЯ»
}

\author{
(c) 2020 Сидорова Наталья Георгиевна \\ кандидат экономических наук, профессор кафедры инноватики, качества, \\ стандартизации и сертификации, Инженерная школа \\ Дальневосточный федеральный университет, Россия, Владивосток \\ E-mail: Sidorova.n0656@yandex.ru
}

(c) 2020 Дружинина Анастасия Романовна

бакалавр кафедры инноватики, качества, стандартизации и сертификации, Инженерная школа

Дальневосточный федеральный университет, Россия, Владивосток

E-mail: nastya18dr@gmail.com

ГЧП определяет широкий спектр партнерских отношений в диапазоне комплексных, технически сложных проектов по реализации мусорных отходов жизнедеятельности человека, включающих строительство, модернизацию, эксплуатацию объектов и управление ими. В развитых странах четко прослеживается настрой в партнерских отношениях в плане увеличения общественного благосостояния и улучшения экологии территории. Сущностью и главной целью ГЧП является создание более эффективной системы производства, чем просто финансирование инвестиционных потребностей инфраструктуры региона по утилизации отходов. С января 2019 года в России ввели поправки в систему обращения с отходами. Изменились принципы и механизмы сбора, сортировки, переработки и утилизации мусора. Основная цель нововведений - решить проблему с полигонами, увеличить количество мощностей по переработке и снизить социальную напряженность по данному направлению государственной политики. Для успешной реализации проектов по утилизации отходов применяется форма ГЧП, что позволяет максимально ускорить улучшение ситуации с РСО в стране.

На данный момент наиболее популярным среди регионов РФ способом утилизации отходов является захоронение - высокотоксичные и малоэффективные, что не подходит под концепцию проекта «Экология».

В статье представлено решение и экономическое обоснование эффективности применения предложенного варианта строительство ЭТП ТОКЧИН по раздельному сбору отходов на территории региона.

Ключевые слова: государственно-частное партнерство, раздельный сбор отходов, публичный партнер, экологический оператор, эффективность проекта.

Модернизация экономики и общества является генеральным направлением развития Российской Федерации на современном этапе.

Необходимо техническое обновление материальной базы, перестройка структуры и диверсификация общественного производства на основе эффективной экономической политики. Россия должна стать страной, в которой благосостояние общества обеспечивается не сырьевыми ресурсами, а современной экономикой, основанной на знаниях, инновациях, высоком уровне развития человеческого капитала.

Особенное внимание обществом и бизнесом уделяется огромной проблеме раздельного сбора отходов (далее - РСО) всех классов с последую- щей переработкой и производством продукции из вторсырья как наиболее экологичным и экономически выгодным решением [8]. Ежегодно образуются миллионы тонн мусора, в 2019 году число твердых отходов, образуемых на планете, превысило 1290 млн. тонн. Прогнозируется, что ближайшие 5 лет количество будет расти, однако если принимать необходимые меры, вместо проектов полигонов по захоронению отходов финансы будут распределяться между проектами в сфере зелёных технологий.

Российская Федерация входит в топ 3 среди стран-производителей бытовых отходов (США на первом месте, Китай на втором). В России образуется около 5,4 миллиарда тонн (средне- 
годовое значение за период 2013-2017 гг.) бытовых, сельскохозяйственных, промышленных и иных видов отходов, из которых 55-60 млн. тонн составляют ТКО, что составляет около 400 кг отходов на 1 человека в год. Подавляющее большинство сырья отправляется на полигоны (рисунок 1). В 2018 году их площадь была 5 млн. гектар. По прогнозам к 2026 г.- увеличится до 8 млн. Таким образом прирост в год составляет 0,4 млн. гектар (суммарная площадь Москвы и Санкт-Петербурга) [2, 9].

Для успешной реализации проектов по утилизации отходов применяется форма ГЧП [1], приняты соответствующие законодательные акты: Федеральный закон «Об особых экономических зонах в РФ» (2005г.), ФЗ «Соглашения о разделе продукции» (1995 г.), «О концессионных соглашениях» (2005 г.). В России уже более 10 лет функционируют промышленнопроизводственные, технико-внедренческие, туристско-рекреационные и портовые зоны. Накоплен существенный опыт взаимодействия федеральных, региональных и муниципальных властей по вопросам финансирования, налогообложения, таможенного регулирования и др. Вместе с тем модернизация становится общенациональной стратегией во всех сферах общественного производства, что обеспечивает мобилизацию и концентрацию всех ресурсов страны для решения ее задач.
В соответствии с указом Президента Российской Федерации № 204 «О национальных целях и стратегических задачах развития Российской Федерации на период до 2024 г.» разработан национальный проект «Экология» [5], в рамках которого планируются к реализации федеральные и соответствующие региональные проекты на период 2019-2024. На основании проекта «Экология» разработана «Комплексная система обращения с твердыми коммунальными отходами», утвержденная Губернатором Приморского края Кожемяко О.Н. [7], в соответствии с которой с 1 января 2020 года Приморский регион перешел на принципиально новый способ обращения с твердыми коммунальными отходами. Теперь вся работа по вывозу и утилизации мусора направлена на наращивание объемов переработки вторсырья и рекультивации старых полигонов. Управлять всем процессом будет единая организация - КГУП «Приморский экологический оператор» [4]. В Приморье действует порядка 60 площадок для размещения отходов, которые соответствуют всем необходимым нормам [3]. В тринадцати из них размещается исключительно бытовой мусор - ТКО.

Цель проекта «Комплексная система обращения с твердыми коммунальными отходами на территории Приморского края» на 2019-2024 г. (см. таблицу 1) - эффективное обращение с отходами производства и потребления, в т.ч. за

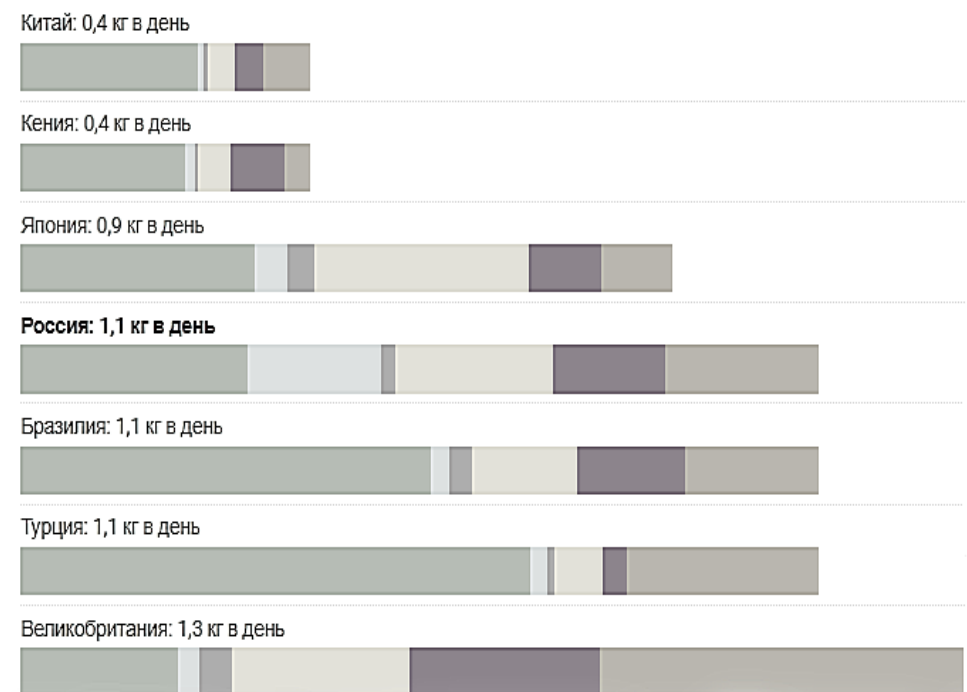

США: 2,2 кг в день

Рисунок 1. Количество производимого мусора по странам (удельная норма на человека) 
Таблица 1. Реализация регионального проекта на 2019-2024 г.

\begin{tabular}{|c|c|c|c|c|c|c|c|}
\hline \multirow{2}{*}{ Наименование показателя } & \multirow{2}{*}{$\begin{array}{l}\text { Базовое } \\
\text { значение }\end{array}$} & \multicolumn{6}{|c|}{ Период, год } \\
\hline & & 2019 & 2020 & 2021 & 2022 & 2023 & 2024 \\
\hline \multicolumn{8}{|c|}{ Доля ТКО, направленных на обработку в общем объеме образованных ТКО, \% } \\
\hline $\begin{array}{l}\text { Доля ТКО, образующихся в Приморском крае, } \\
\text { направленных на обработку в общем объеме } \\
\text { образованных ТКО, \% }\end{array}$ & 7 & 12 & 27 & 38 & 40 & 55 & 60 \\
\hline \multicolumn{8}{|c|}{$\begin{array}{c}\text { Доля городского населения РФ, обеспеченного качественной питьевой водой } \\
\text { из систем центрального водоснабжения }\end{array}$} \\
\hline $\begin{array}{l}\text { Доля ТКО, образующихся в Приморском крае, } \\
\text { направленных на утилизацию в общем объеме } \\
\text { образованных ТКО, \% }\end{array}$ & 3 & 4 & 5 & 7 & 8 & 10 & 13 \\
\hline
\end{tabular}

счет ввода в промышленную эксплуатацию 70,6 тыс. т/год мощностей по утилизации отходов и фракций после обработки ТКО и 325,7 тыс. т/год мощностей по обработке ТКО, что приведет к увеличению доли ТКО, направленных на утилизацию до 13\% и обработку до 60\%, в общем объеме образованных твердых КО, к 2024 году.

Вопрос повышения экономической отдачи от утилизации и перехода на новую систему обращения с твердыми бытовыми отходами, рекультивации свалок в Приморском постоянно присутствует в программах развития региона в национальном проекте «Экология», который сегодня реализуется в Приморье. Он включает два региональных проекта, тесно связанных между собой: «Комплексная система обращения с TKO» и региональный проект «Чистая страна». Первый проект является основой обращения с TKO, а второй направлен на избавление от накопленного мусора, на ликвидацию свалок. Компания «Приморский экологический оператор» осуществляет сбор, транспортировку, обработку, утилизацию, обезвреживание и захоронение отходов. Тарифы на услугу регионального оператора по обращению с твердыми коммунальными отходами КГУП «Приморский экологический оператор», осуществляющего деятельность на территории Приморского края на 2020 год, в соответствии с Приложением к постановлению департамента по тарифам Приморского края от 19.12.2019 N 65/18 [6].

Основными задачами на сегодняшний день названы:

- внедрение раздельной системы сбора мусора на территории Приморья;

- контроль над потоками отходов, создание прозрачной системы обращения с отходами, информирование и просвещение жителей края по экологическим вопроса;
- ликвидация несанкционированных свалок в соответствии с законодательством Российской Федерации;

- создание мусороперегрузочных, перевозочных станций;

- извлечение полезных компонентов из отходов, безопасное размещение не утилизируемых отходов и их компонентов, построение объектов по обработке и утилизации отходов.

Здесь государственно-частное партнерство создает конкретные модели отношений собственности, методов управления и способов финансирования. В этой связи проект функционирования ГЧП предполагает не только сложение ресурсов государства и бизнеса, но и определение набора правомочий сторон в соответствии с критерием эффективности использования этих ресурсов.

Объектом применения ГЧП и существующих мер по раздельному сбору отходов, технологические решения для организации РСО в г. Владивостоке и кампусе Дальневосточного Федерального Университета уделяется особое внимание.

Владивосток один из крупнейших портов Дальнего Востока, административный центр Приморского края, входит в состав Владивостокского городского округа, конечный пункт Транссибирской магистрали. Население города 605 тысяч человек (данные за 2019 год).

Актуальность экологической ситуации для Владивостока с каждым месяцем только растет. В городе ежегодно растет население, производство и, соответственно, выбросы твердых, жидких и газообразных отходов. Основным предложением по улучшению ситуации с раздельным сбором отходов на территории кампуса ДВФУ является создание системы, которая будет работать вне зависимости от внешних рисков: инфляции, политического аспекта, логистических 
ресурсов и пр. Таким решением будет являться комплекс замкнутого цикла переработки - от сбора отходов с территории кампуса до использования вторсырья для производства новых изделий и органической продукции. Ключевой задачей появления Экотехнопарка (далее - ЭТП) на территории кампуса ДВФУ второй волны застройки будет являться развитие системы обработки и обезвреживания отходов с внедрением новейших технологий и привлечением потенциала научных и образовательных учреждений, а также создание экономической зоны со специальным налоговым режимом.

Проект имеет комплексную бизнес-модель (рисунок 2): производитель, агрегатор, франшиза. На начальном этапе приоритетными будут услуги по переработке отходов и производство органически-чистого удобрения.

Необходимые финансы для реализации проекта ЭТП ТОКЧИН на данный момент оценива- ются в 500 млн. руб. Данная сумма необходима для запуска проекта, дальнейший процесс будет автоматизирован внутри системы и дополнительные финансовые ресурсы не потребуются

Суммарные капитальные затраты на строительство ЭТП ТОКЧИН определены в ценах 2019 г. в объеме 430,5 млн. руб. в таблице 2.

При создании данного бизнеса будут использованы фискальные платежи в соответствии с Федеральным законом от 24.07.2007 № 209-ФЗ «О развитии малого и среднего предпринимательства в Российской Федерации», ставки по налоговым и страховым взносам представлены в таблице 3.

В таблице 4 представлены ключевые показатели проекта ЭТП ТОКЧИН, из анализа которых можно сделать вывод об эффективности внедрения данного инструмента в г. Владивосток, кампус ДВФУ.

\begin{tabular}{|c|c|c|c|c|}
\hline \multirow{2}{*}{$\begin{array}{l}\text { Ключевые партнеры } \\
\text { Правительство } \\
\text { Приморского края } \\
\text { Фонды поддержки } \\
\text { инноваций } \\
\text { Производственные } \\
\text { предприятия }\end{array}$} & $\begin{array}{l}\quad \text { Ключевые действия } \\
\text { 1.Сортировка отходов } \\
\text { 2.Переработка } \\
\text { утилизация отходов } \\
\text { 3.Создание продукции из } \\
\text { вторичных ресурсов }\end{array}$ & \multirow{3}{*}{\begin{tabular}{l}
\multicolumn{1}{l}{ Ключевые действия } \\
1.Улучшение \\
экологической \\
обстановки \\
2.Снижение \\
себестоимости \\
продукции \\
3.Биотопливо для \\
заправки транспорта \\
4.Уменьшение площади \\
земель, занятых \\
свалками
\end{tabular}} & $\begin{array}{l}\quad \text { Каналы сбыта } \\
\text { Партнерские } \\
\text { Продажные } \\
\text { Информационные } \\
\text { Постпродажный }\end{array}$ & \multirow{2}{*}{\begin{tabular}{l}
\multicolumn{1}{c}{ Взаимоотношения с } \\
клиентами \\
В2С - предложение \\
более доступного \\
экологичного продукта \\
В2В - резидентство, \\
предложение льгот, \\
франшиза \\
В2G - участие в \\
госпрограммах, \\
конкурсах, создание \\
замкнутой экосистемы, \\
улучшающей уровень \\
жизни населения
\end{tabular}} \\
\hline & $\begin{array}{l}\text { Ключевые ресурсы } \\
\text { 1.Рабочие места } \\
\text { 2.Уникальные } \\
\text { технологии }\end{array}$ & & $\begin{array}{c}\text { Потребительский } \\
\text { сегмент } \\
\mathrm{B} 2 \mathrm{C}, \mathrm{B} 2 \mathrm{~B}, \mathrm{~B} 2 \mathrm{G}\end{array}$ & \\
\hline \multicolumn{2}{|c|}{$\begin{array}{l}\text { Структура расходов } \\
\text { 1.Приобретение установки по переработке и } \\
\text { утилизации промышленных отходов } \\
\text { 2.Подготовка документации (патент, лицензия) } \\
\text { 4.Участок земли } \\
\text { 5.Подготовка инфраструктуры }\end{array}$} & & \multicolumn{2}{|c|}{$\begin{array}{l}\text { 1. Продажа органически чистой продукции, } \\
\text { топлива } \\
\text { 2. Продажа от франшизы }\end{array}$} \\
\hline
\end{tabular}

Рисунок 2. Бизнес модель ЭТП

Таблица 2. Затраты на проект ЭТП ТОКЧИН

\begin{tabular}{|l|c|}
\hline \multicolumn{1}{|c|}{ Наименование } & Значение (руб.) \\
\hline Проектирование & 39680900 \\
\hline Общестроительные работы & 66724100 \\
\hline Монтаж оборудования & 17884600 \\
\hline ПНР & 20035000 \\
\hline Оборудование комплекса по переработке отходов & 286214500 \\
\hline Всего & $\mathbf{4 3 0 5 3 9 2 0 0}$ \\
\hline
\end{tabular}


Таблица 3. Виды налогов и страховых взносов, необходимых к уплате проектом

\begin{tabular}{|l|c|}
\hline \multicolumn{1}{|c|}{ Виды отчислений } & Ставка, \% \\
\hline НДС (применяется УСНО) & 0,0 \\
\hline УСН & 6,0 \\
\hline ФОМС (субъект МСП) & 5,0 \\
\hline ФОПС (субъект МСП) & 10,0 \\
\hline ПФР (как резидент Сколково) & 14,0 \\
\hline ФСС на случай временной нетрудоспособности и в связи с материнством & 0,0 \\
\hline
\end{tabular}

Таблиц̧ 4. Ключевые показатели проекта

\begin{tabular}{|l|l|}
\hline \multicolumn{1}{|c|}{ Наименование показателя } & \multicolumn{1}{c|}{ Значение } \\
\hline Себестоимость & 430,5 млн. руб. \\
\hline Выручка & 815,6 млн. руб. \\
\hline IRR & $21,2 \%$ \\
\hline Окупаемость & 2,5 года \\
\hline Рабочие места & $400-450$ чел. \\
\hline Производительность & $\begin{array}{l}\text { 300000 тонн/год отходов, в т.ч. } \\
\text { 200000 тонн/год ТКО }\end{array}$ \\
\hline Площадь (с 4 теплицами) & 20 Га \\
\hline Продукция & $\begin{array}{l}\text { Вторсырье; } \\
\text { Удобрения; } \\
\text { Тепло и электроэнергия; } \\
\text { Биотопливо (синтез-газ, биогаз, паллеты, брикеты и др.); } \\
\text { Стройматериалы (пластиковые трубы, резиновая крошка, полимер- } \\
\text { песчаные изделия, щебенка, эко-вата и др.); } \\
\text { Продукция из вторсырья (туалетная бумага, ведра, садовый инвентарь, } \\
\text { детские игровые площадки и др.); } \\
\text { Продукты органического земледелия (огурцы, томаты, зелень, перец, } \\
\text { клубника, редиска и др.). }\end{array}$ \\
\hline
\end{tabular}

Значительный объем отходов, который будет не захоронен на полигонах, а собран и вывезен при помощи мощностей ЭТП ТОКЧИН приведет к естественному очищению кампуса и созданию благоприятной экологической обстановки в г. Владивосток и Приморском крае.
Предлагаемое решение проект Экотехнопарк «ТОКЧИН», реализованный совместно с ООО «ТОКЧИН» - это эффективный, социальнонеобходимый, многофункциональный комплекс, который будет реализован под национальные цели и проект «Экология».

\section{Библиографический список}

1. Государственно-частное партнерство как инструмент индустриализации российской экономики, Известия Дальневосточного Федерального Университета, экономика, Сидорова Н. Г., Савченко И. И. 2014, с.3-11

2. Доля перерабатываемых отходов в России Электрон. дан. // Журнал Тинькофф URL: https://journal.tinkoff. ru/garbage/ (дата обращения 12.04.2020);

3. Загрязненные районы Владивостока Электрон. дан. // Новостной ресурс URL: https://primpogoda.ru/news/ ecology/samye_zagryaznennye_rajony_vladivostoka_v_yanvare (дата обращения 22.04.2020);

4. Закон Приморского края об отходах производства и потребления в Приморском крае № 447 от 27.05 .2009 Электрон. дан. // Региональный оператор Приморье URL: http://spzv.ru/wp-content/uploads/2018/08/ZakonPrimorskogo-kraya-N-447-KZ--Ob-othodah-proizvodstva-i-potrebleniya-v-Primorskom-krae (дата обращения 01.05.2020); 
5. Национальный проект «Экология» Электрон. дан. // Национальный проект «Экология» URL: https://нацпроектэкология.рф (дата обращения 01.05.2020);

6. Приложение к постановлению департамента по тарифам Приморского края от 19.12.2019 N 65/18 Электрон. дан. // TЕХЭКСПЕРТ URL: http://docs.cntd.ru/document/561690551 (дата обращения 22.04.2020);

7. Региональный проект «Комплексная система обращения с твердыми коммунальными отходами», утвержденным Губернатором Приморского края Кожемяко О.Н. в презентации Елены Пархоменко (дата обращения 22.03.2020);

8. Рогозин М. Ю. Практика внедрения раздельного сбора мусора в разных странах мира // Молодой ученый / М. Ю.Рогозин, Е.А. Бекетова.-2018. - № 25.- С. 25-28;

9. Статистика производства бытовых отходов в РФ Электрон. дан. // Всё о переработке и утилизации отходов URL: https://musorish.ru/problema-musora-v-rossii/ (дата обращения 10.04.2020); 